\title{
IEMANJÁ E IANSÃ NA SALA DE AULA: DIÁLOGOS SOBRE RELIGIÃO AFRICANA NA LITERATURA JUVENIL BRASILEIRA
}

\author{
Iemanjá and Iansã in the classroom: dialogues about African religion in \\ Brazilian youth literature
}

\author{
Marcilene Moreira DONADONI \\ Universidade Federal de Mato Grosso do Sul \\ marcilenemdonadoni@hotmail.com \\ https://orcid.org/0000-0001-7079-6727
}

\begin{abstract}
RESUMO: Baseado na determinação da Lei $\mathrm{n}^{\circ} 10.639$, de 9 de janeiro de 2003, acerca do ensino de História e Cultura Afro-brasileira, este trabalho apresenta uma descrição das aulas de literatura desenvolvidas por meio da leitura de textos afro-brasileiros de temática religiosa. Para tanto, analisar-se-á a recepção de dois contos curtos: "A pele de OiáIansã", de Celso Sisto, e "A punição de Iemanjá", de Adilson Martins, realizadas por meio de atividades de leitura e produção de texto aplicadas ao $2^{\circ}$ ano do Ensino Médio, da Escola Estadual Edwards Corrêa e Souza, localizada no município de Três Lagoas (MS). Assim, ancorados metodologicamente nos pressupostos teóricos de Bonnici (2011), Conceição (2016), Mariosa e Reis (2011), Mereilles (2012) e Oliveira (2013), propomos discutir o papel da escola e da literatura na formação da identidade dos estudantes praticantes das religiões de matriz africana - candomblé e umbanda. Dessa forma, verificamos a partir da pesquisa-ação que esse perfil de estudantes se encontra silenciado e oprimido em contexto escolar. Logo, traçamos sequências didáticas que permitiram atenuar essa condição, destacando a importância da luta social das personagens negras Iemanjá e Iansã.
\end{abstract}

PALAVRAS-CHAVE: Formação da Identidade; Lei $\mathrm{n}^{\mathrm{o}}$ 10.639; Literatura Juvenil Afro-brasileira.

\begin{abstract}
Allegedly based on the law number 10.639, from January 9th, 2003, about the Afro-Brazilian History and Culture teaching, this paper presents a description of the literature classes developed through the Afro-Brazilian texts reading with the religious theme. Therefore, we will analyze the reception of two short stories "The skin of Oiá-Iansã", by Celso Sisto, and "The punishment of Iemanjá", by Adilson Martins, fulfilled through reading activities and text production applied on the 2nd grade of High School, from Edwards Corrêa e Souza State School, located in Três Lagoas City (MS). Thus, methodologically anchored in the Bonnici (2011), Conceição (2016), Mariosa and Reis (2011), Mereilles (2012) and Oliveira (2013) theoretical assumptions, we want to discuss the school and literature role in the students' identity
\end{abstract}


formation, who are African origin religions' followers - Candomblé and Umbanda. Therefore, we verified through this action-research that these students' profiles are silenced and oppressed in the school setting. Therefore, we developed didactic sequences that allowed lessening this condition, underscoring the importance of the social fight of the black skin characters Iemanjá and Iansã.

KEYWORDS: Identity Formation; Law number 10.639; Afro-Brazilian Youth Literature.

\section{INTRODUÇÃO}

No atual cenário da educação brasileira, estudar, refletir e resgatar a cultura afrobrasileira na escola deixou de ser apenas um direito garantido pela Lei $n^{\circ} 10.639$, de 9 de janeiro de 2003, que altera a Lei $\mathrm{n}^{\circ}$ 9.394, de 20 de dezembro de 1996, e estabelece as diretrizes e bases da educação nacional, para incluir no currículo oficial da Rede de Ensino, a obrigatoriedade da temática História e Cultura Afro-Brasileira, preconizando que:

[...] Art. 26-A. Nos estabelecimentos de ensino fundamental e médio, oficiais e particulares, torna-se obrigatório o ensino sobre História e Cultura Afro-Brasileira.

$\S 1^{\circ} \mathrm{O}$ conteúdo programático a que se refere o caput deste artigo incluirá o estudo da História da África e dos Africanos, a luta dos negros no Brasil, a cultura negra brasileira e o negro na formação da sociedade nacional, resgatando a contribuição do povo negro nas áreas social, econômica e política pertinentes à História do Brasil.

$\S 2^{\circ}$ Os conteúdos referentes à História e Cultura Afro-Brasileira serão ministrados no âmbito de todo o currículo escolar, em especial nas áreas de Educação Artística e de Literatura e História Brasileiras.

[...] "Art. 79-B. O calendário escolar incluirá o dia 20 de novembro como 'Dia Nacional da Consciência Negra'. (BRASIL, Lei no 10.639, 2003).

E assim passa a ser dever da comunidade escolar, enquanto prática social que oportunize, favoreça e valorize a construção da identidade dos estudantes praticantes das religiões de matrizes africanas, como candomblé e umbanda, uma vez que a Lei no 10.639 possibilite o ensino da História e Cultura Afro-Brasileira em sala de aula.

A questão da cultura africana, nesse caso das religiões afro-brasileiras, e seu debate no espaço escolar estão longe de ser uma questão que diga respeito exclusivamente aos afro-descendentes ou praticantes das religiões afrobrasileiras, negros ou não, pois nos remete a uma 
compreensão mais profunda sobre a nossa própria sociedade (OLIVEIRA et al., 2013, p. 272).

Nessa perspectiva, rememorar e compreender a formação do Brasil, a partir da perspectiva histórica, é importante, porém a narrativa na visão do historiador é composta, em sua maioria, por elementos de caráter informativo, que carecem de literariedade, ou seja, que possibilitem a reflexão, a partir da polissemia, assim como a formação humana dos estudantes, especialmente por meio do retrato social.

De acordo com os estudos de Ginzburg (2000), o livro de história apresenta "a experiência crua do passado violento e autoritário, incluindo os massacres da inquisição, o escravismo exploratório, a repressão patriarcal, constitui uma série de traumas" (GINZBURG, 2000, p. 50), sem realizar, necessariamente, uma reflexão sistemática que priorize os contextos sociais das personagens do passado, como os negros escravizados, por exemplo.

Por outro lado, a literariedade, característica essencial do que é literário, concerne ao estudante, segundo Candido (2011), o desenvolvimento e/ou manutenção de sua função social, pois a literatura, por meio de seu caráter humanizador, “confirma e nega, propõe e denuncia, apoia e combate, fornecendo a possibilidade de vivermos dialeticamente os problemas" (CANDIDO, 2011, p. 177).

Assim, este trabalho se concentra em descrever as aulas de literatura do $2^{\circ}$ ano do Ensino Médio, da Escola Estadual Edwards Corrêa e Souza, localizada no município de Três Lagoas (MS), desenvolvidas a partir da leitura e análise de dois contos de literatura afro-brasileira juvenil de temática religiosa1: "A punição de Iemanjá”, de Adilson Martins, e "A pele de Oiá-Iansã”, de Celso Sisto.

De acordo com Santos e Wielewicki (2009, p. 342), na esteira de Bernd (1987, p.80), ao apresentarem alguns critérios para classificar a literatura afro-brasileira destacam-na como "uma literatura empenhada em resgatar uma ancestralidade africana". Dessa forma, os contos selecionados para serem aplicados em sala de aula classificam-se como afro-brasileiros por seu critério temático, ou seja, “[...] conteúdo literário relacionado aos temas referentes à cultura afro-brasileira" (SANTOS; WIELEWICKI,

\footnotetext{
${ }^{1}$ Os contos selecionados são aprovados pelo Ministério da Educação (MEC) e disponibilizados pelo Fundo Nacional de Desenvolvimento da Educação (FNDE), especialmente para serem utilizados em ambiente 
2009, p. 342).

Acreditamos que refletir sobre as sequências didáticas relacionadas às religiões afro-brasileiras ampliem seu espaço no ambiente escolar, tendo em vista a oportunidade de compartilhar com a comunidade escolar estratégias pontuais acerca dessa temática, corroborando a ampliação do diálogo sobre literatura afro-brasileira, especialmente a de temática religiosa.

\section{A RELIGIÃo AFRO-BRASILEIRA E O CURRÍCULO ESCOLAR}

Ao analisarmos a presença e/ou as representações culturais e religiosas afrobrasileiras no ambiente escolar, deparamo-nos com "[...] manifestações de racismo, discriminação social e étnica, por parte de professores, de alunos, da equipe escolar, ainda que de maneira involuntária ou inconsciente" (BRASIL, 1997, p. 122).

Desse modo, é importante ressaltarmos que, segundo os Parâmetros Curriculares Nacionais (PCN), a escola "[...] é um espaço em que pode se dar a convivência entre estudantes de diferentes origens, com costumes e dogmas religiosos diferentes daqueles que cada um conhece, com visões de mundo diversas daquela que compartilha em família" (BRASIL, 1997, p. 123).

A sequência didática a ser apresentada referência a necessidade de práticas interdisciplinares desenvolvidas a partir de um tema comum, como as diferentes religiões praticadas ou não no Brasil, com o intuito de romper com a hegemonia religiosa que se instaurou desde a colonização do país com a catequização dos indígenas.

\footnotetext{
Soma-se a isso o crescimento de professores evangélicos que, ao invés de informar sobre as religiões existentes no Brasil, acabam por fazer proselitismo na sua prática pedagógica. $\mathrm{O}$ ambiente escolar acaba por contribuir para o fracasso e evasão escolar, já que determinados alunos são vitimizados, inferiorizados, não se reconhecendo enquanto centro do processo ensino-aprendizagem (CONCEIÇÃO, 2016, p. 118).
}

Nessa perspectiva, a revisão do currículo escolar e sua reorganização como um todo articulado que favoreça a interdisciplinaridade seria capaz de contribuir com a manutenção e recepção de diferentes religiões na sala de aula. Essa seria uma forma de 
compreender as diferentes manifestações sociais e culturais, assim como respeitar e viabilizar a construção de identidades dos educandos praticantes de religiões de matrizes africanas. Pois, conforme o PCN, “[...] a afirmação da diversidade é traço fundamental na construção de uma identidade nacional que se põe e repõe permanentemente, tendo a Ética como elemento definidor das relações sociais e interpessoais [...]" (BRASIL, 1997, p.121).

Logo, torna-se relevante analisarmos os estudos e pesquisas atuais que dialogam e refletem o debate acerca das religiões e identidades africanas e afro-brasileiras na sala de aula, destacando suas contribuições para a revisão do currículo escolar e a criação de projetos e práticas de valorização da religiosidade de matrizes africanas.

Mesmo que de forma tímida, discussões relacionadas a religiões marginalizadas têm ganhado fôlego no cenário acadêmico, especialmente as de matrizes africanas, como a umbanda e o candomblé, que se mantêm no Brasil por meio da manutenção da tradição herdada pelos africanos escravizados.

[...] foram instaladas capelas nos navios negreiros para que se batizassem os escravos antes da travessia. Em total desrespeito e flagrante violação à religião dos africanos, a preocupação cristã consistia em salvar as almas e deixar os corpos morrerem! Aliás, parte dos missionários mostrou-se até incapaz de aceitar que eles possuíssem uma religião e, quando o foi, chamaram-na de animismo, com o intuito de ressaltar que os negros botavam alma nas pedras, nas árvores e em todos os objetos animados e inanimados de seu meio ambiente (MUNANGA, 2009, p. 29).

Em sua maioria são pesquisas que procuram apresentar e romper com os estigmas construídos desde a colonização do Brasil, período em que os africanos eram trazidos como escravos, sofrendo perda de sua identidade cultural e religiosa por meio das violentas imposições do colonizador.

As religiões de matriz africana sempre se firmaram como elo de resistência e luta pela liberdade do povo negro, desde os primeiros dias do cativeiro até os dias atuais. Ao contrário, há vários relatos que dão conta de proibição, prisão e cerceamento; inicialmente, das práticas do candomblé, e, mais tarde, da umbanda (CONCEIÇÃO, 2016, p. 116).

Entretanto, a visão proposta por Conceição (2016) de que a religião africana representa um elo de resistência ao sistema escravocrata é silenciada e vilipendiada, 
sobretudo, pela tradição religiosa cristã, a qual sempre condenou e rotulou como pertencente ao Demônio tudo aquilo que fosse diferente de sua doutrina sacra. Debate que tem ganhado força a partir da lei $n^{\circ} 9.459$, de 15 de maio de 1997 , que considera crime a prática de discriminação ou preconceito contra as religiões.

Outras formas de racismos e preconceitos eram praticadas em sala de aula, tais como a apresentação das culturas africanas, sobretudo os aspectos religiosos, que eram associados a bruxaria, feitiçaria ou magia negra, em detrimento da hegemonia católica da elite branca (CONCEIÇÃO, 2016, p. 114-115).

Nessa perspectiva tradicionalista, discutir religião em sala de aula está limitado ao ensino de valores cristãos católicos. Logo, devido ao crescente número de discentes e docentes evangélicos, os valores protestantes que centralizam as discussões e desconsideram as demais religiões existentes no Brasil têm sido incorporados ao currículo, influenciados, especialmente, pela predileção religiosa do docente, pois "[...] reduzem a Lei ${ }^{\circ} 10.639 / 2003$ apenas à questão religiosa, esquecendo-se de que a aplicação da lei diz respeito a um conjunto de temas relativos ao continente africano e à sociedade brasileira [...]" (CONCEIÇÃO, 2016, p. 121).

Por isso, os estudos desenvolvidos acerca da religiosidade africana concentram-se, em sua maioria, em romper e/ou atenuar o estereótipo negativo que se consagrou desde a colonização e se difundiu com as doutrinas religiosas dominantes. Pois existe, ainda, a imposição e a condenação do colonizador sobre a construção de valores e da identidade candomblecista e umbandista dos estudantes.

De acordo com Meirelles (2012, p. 151), para a realização de ações que possibilitem discutir religiosidade em sala, ao invés de religião, é importante "a promoção em sala de aula, de reflexões conceituais que permitam [...] desmistificar noções já naturalizadas em livros e outros materiais didáticos acerca daquilo que se entende por raça, cor, etnia, identidade, entre outros".

Contudo, são poucos os docentes que se propõem a realizar tal reflexão em sala de aula. Ao pensarmos nas religiões africanas, os professores que a estudam em ambiente escolar, em sua maioria, frequentam ou já frequentaram um terreiro, são praticantes de candomblé ou da umbanda e, consequentemente, foram vítimas de preconceito religioso. 
Assim, na medida em que o docente candomblecista ou umbandista realiza discussões religiosas em sala de aula, o preconceito enraizado se expande, por meio de discursos de ódio advindos do passado, os quais emanam da comunidade escolar e ganham motivação por meio dos defensores dos valores cristãos. Isso gera, em muitos casos, o silenciamento de discentes e docentes.

Nesse segmento, é essencial que a discussão seja partilhada e não centralizada ou influenciada pela religião do docente. Isso é importante uma vez que o objetivo de toda aula, de qualquer disciplina, é mediar o conhecimento e possibilitar a inclusão de alunos que, até então, são silenciados e condenados pela sociedade cristã, pelo discurso do professor, do livro didático ou dos colegas de sala, por meio dos valores religiosos consagrados que ecoam em seus discursos.

Conforme Meirelles (2012, p. 153) cabe a todo “[...] professor que adentra as salas de aula da Educação Básica a tarefa de estabelecer um diálogo entre os conteúdos escolares e a realidade na qual o discente está inserido", rompendo com a tradição que perpetua discursos canonizados que, em sua construção, foram motivados por ódio e preconceito.

Outra questão importante, é que ao pensarmos a relação entre as religiões afro-brasileiras e a escola, somos instigados a refletir sobre que modelo de sociedade é apresentado na educação formal brasileira e quais as implicações para os alunos ao se deparar com este. Ao mesmo tempo devemos ir além, cabe nos questionar quais outros modelos de sociedade são possíveis e quais projetos estão em disputa (OLIVEIRA et al., 2013, p. 276).

Com base no discurso de Oliveira (2013) podemos definir o papel do professor contemporâneo como um sujeito mediador, ou seja, aquele capaz de mediar tanto o conteúdo, quanto de criar e apresentar caminhos que possibilitem aos alunos conviverem em uma sociedade livre de padrões religiosos tradicionais centrados em julgar e condenar tudo o que consideram diferente de si.

Para tanto, as discussões e a sequência didática desenvolvidas nesta pesquisa visam primeiramente conceder voz e lugar ao aluno candomblecista e umbandista que se encontra, hoje, silenciado em sala de aula, com medo de expor sua visão religiosa, pois conhece apenas uma realidade: a do preconceito instaurado. Porque falar em religião afro- 
brasileira em sala de aula é libertar os alunos de um passado de opressão, violência e silenciamentos.

\section{METODOLOGIA}

Partindo da premissa de que o: "[...] processo de compreensão e melhoria de seu trabalho deve começar pela reflexão de sua própria experiência [...]" (DINIZ-PEREIRA; ZEICHNER, 2005, p. 66), este trabalho configura-se metodologicamente como uma pesquisa-ação, ou seja, "uma pesquisa sistemática feita por profissionais sobre as suas próprias práticas" (Ibid., p. 65).

A pesquisa-ação possibilita compreender e valorizar o trabalho do professor enquanto pesquisador, especialmente porque "[...] os profissionais produzem teorias que os ajudam a tomar decisões no contexto prático [...]" (DINIZ-PEREIRA; ZEICHNER, 2005, p. 66), uma vez que o docente consegue a partir de problemas comuns e rotineiros criar soluções efetivas e, em sua maioria, simples, ou seja, a partir de metodologias e práticas diferenciadas.

\footnotetext{
Acreditamos que a participação dos profissionais e, mais especificamente, dos educadores, em projetos de pesquisa-ação, ou seja, o envolvimento direto deles com o processo de produção sistemática de um saber extremamente relevante e essencial para suas práticas, pode transformá-los também em "consumidores" mais críticos do conhecimento educacional gerado nas universidades. Isso pode acontecer porque esses sujeitos passariam a compreender melhor como tal conhecimento é produzido nos meios acadêmicos (DINIZ-PEREIRA; ZEICHNER, 2005, p. 66).
}

A investigação centrada no desenvolvimento de sequências didáticas acerca da leitura de textos literários juvenis afro-brasileiros se enquadra no paradigma qualitativo, pois, na visão de Gomes (2009, p. 79), “[...] seu foco é, principalmente, a exploração do conjunto de opiniões e representações sociais sobre o tema que pretende investigar [...]".

Sendo assim, para o desenvolvimento da pesquisa, elencou-se como público alvo os estudantes da rede pública do segundo ano do Ensino Médio, da Escola Estadual Edwards Corrêa e Souza, localizada no município de Três Lagoas (MS), a qual realiza e valoriza as discussões acerca da identidade afro-brasileira dos estudantes. 
Dessa forma, o conteúdo e a sequência didática foram embasados e desenvolvidos a partir de dois contos afro-brasileiros juvenis de temática religiosa: "A punição de Iemanjá”, de Adilson Martins, e “A pele de Oiá-Iansã”, de Celso Sisto, os quais foram lidos e analisados em sala de aula pelos estudantes. Essas atividades aconteceram por meio de rodas de leituras, debate, exercícios de interpretação e produção de texto, que colaboraram como instrumento de coleta de dados.

Assim, o tópico "Desenvolvimento" apresenta a descrição e revisão da prática desenvolvida em sala de aula a partir da leitura dos contos afro-brasileiros juvenis, tendo como foco principal o aluno enquanto sujeito em formação e a influência da literatura nesse processo, com o intuito de criar uma sequência didática sólida e coerente que possa ser utilizada por outros docentes, ampliando as discussões sobre a presença e recepção da religiosidade afro-brasileira na sala de aula, por meio de textos literários.

\section{POR QUE FALAR DE RELIGIÃO NA ESCOLA?}

O corpus desse trabalho foi selecionado a partir de três pontos centrais que motivam situações de silenciamento e opressão de estudantes em sala de aula, especialmente ao discutir ou mencionar a temática religiosidade em ambiente escolar, sendo eles: 1. A mulher; 2. A mulher negra; e 3. A mulher negra candomblecista e/ou umbandista.

A inter-relação desses três itens constrói a identidade dos estudantes que mais sofrem com o preconceito, a discriminação e o apagamento de subjetividades outras em sala de aula, sendo em sua maioria mulheres negras praticantes ou que possuem alguma ligação, por parentesco ou curiosidade, com as religiões de matriz africana.

Como intuito de modificar esse cenário opressor, a sequência didática aplicada propõe a leitura de dois contos, os quais possuem protagonistas com identidades semelhantes ao perfil das estudantes silenciadas. Logo, ganham destaque as orixás femininas Iemanjá-Yemanjá e Iansã-Oiá.

Iemanjá é cultuada no Brasil como a mãe dos Orixás, pois, conforme a tradição da umbanda, é mãe de Exu, Ogum, Oxóssi e Obaluaê - este último descrito como um menino doente encontrado na beira do mar, criado como filho por Iemanjá -, por sua relação com as águas salgadas e pelo sincretismo com Nossa Senhora dos Navegantes, protetora dos 


\section{REVISTA $\mathbf{X}$}

pescadores e do mar.

A figura maternal submissa e caridosa da mãe é uma roupagem típica do patriarcalismo ocidental e sua essência se manifesta também na literatura religiosa, tendo Maria, mãe de Jesus Cristo, como um dos principais exemplos de obediência e submissão a figura masculina. Já na tradição africana, Iemanjá não é somente a mãe, sua figura representa o poder, a força e a tempestade, descrita muitas vezes como a água do mar, a qual aparentemente calma, pode subitamente se transformar em tempestade marítima e provocar o caos. Personagem que ganha destaque no conto da tradição oral africana "A punição de Iemanjá", de Adilson Martins.

Em síntese, Iemanjá rouba os objetos sagrados de Ifá, jogo de adivinhação realizado apenas por homens. O responsável pelo Ifá era seu marido Orunmilá, que durante uma viagem deixa os instrumentos sob o cuidado de Exu, o guardião. No entanto, Iemanjá, muito astuta, os rouba, embriagando Exu, e passa a ser a orácula de Ifá, fazendo mais sucesso que o marido. Ao regressar, Orunmilá arranca a força os símbolos de Ifá de Iemanjá e a pune, expulsando-a para o mar, onde reinava seu pai Olokun.

De conformidade, Iemanjá prova que as mulheres possuem tantas habilidades quanto os homens, e ao mesmo tempo destaca o papel da mulher na sociedade, rompendo com os arquétipos patriarcais de esposa submissa "Só não se pode dizer, diante disto, é que Iemanjá não sabe Ifá, nem que as mulheres não sejam capazes de compreender seus mistérios e desvendar seus segredos" (MARTINS, 2008, p. 129).

\footnotetext{
Atualmente, os textos voltados para o público infanto-juvenil, buscam romper com as representações que inferiorizam os negros e sua cultura. As obras os retratam em situações comuns do cotidiano, enfrentando preconceitos, resgatando sua identidade e valorizando suas tradições religiosas, mitológicas e a oralidade africana (MARIOSA; REIS, 2011, p. 45).
}

Iansã é configurada como a orixá guerreira na Umbanda e no Candomblé. Na tradição brasileira, sua força é comparada as fortes rajadas de ventos e raios das tempestades. É sincretizada com Santa Bárbara, divindade católica.

No conto "A pele de Oiá-Iansã", de Celso Sisto, Iansã é tomada a força como esposa por Ogum, que, ao vê-la se metaforizando de búfalo para humana, rouba sua pele e a chantageia ao matrimônio. Segundo a tradição, eles tiveram nove filhos, número da 


\title{
REVISTA $\mathbf{X}$
}

simbologia que a representa.

Ogum possuía outras mulheres que se uniriam contra Iansã, especialmente devido a sua misteriosa beleza. Ao embriagarem o marido, elas descobrem o mistério e passam a zombar dela. Após muito tempo, Iansã recupera sua pele, se transforma em búfalo e chifra todos que a maltratavam, poupando apenas seus filhos.

\begin{abstract}
Vestiu-a imediatamente, aprumou-se e ficou esperando que as outras mulheres retornassem para casa naquele dia. Quando as mulheres abriram a porta da casa, o que viram foi um búfalo enlouquecido, que bufava e chifrava para todos os lados. Foi uma gritaria medonha. $\mathrm{O}$ búfalo não poupou ninguém. Só não fez nada com os nove filhos (SISTO, 2007, p. 105).
\end{abstract}

Iansã foge sozinha para a floresta, mas ao ver seus filhos chorarem, para e entrega seus chifres a eles "- Sempre que estiverem em perigo ou precisarem da minha ajuda, batam um chifre no outro e eu virei, rápida como um raio - Êpa Heyi!" (SISTO, 2007, p.105), demonstrando sua prontidão e coragem para lutar por aqueles que ama.

Notamos que a religiosidade perpassa as narrativas a partir da presença de elementos simbólicos. No entanto, a motivação das tramas se desenvolve por meio da resistência à tradição patriarcal opressora, especialmente pela posição central e heroica que as mulheres ocupam na narrativa.

A leitura de textos advindos da tradição oral africana em sala de aula já não são mais um desafio, ao considerarmos que a Lei $n^{\circ} 10.639$ favoreceu e ampliou sua presença nesse cenário. Todavia, ao destacarmos elementos religiosos africanos como o Ifá e a figura de Iemanjá enquanto orixá da Umbanda e do Candomblé, deparamos com uma linha tênue entre falta de conhecimento e preconceito instaurado.

Em uma primeira leitura, e sendo esta bastante superficial, a religiosidade é atenuada pela linguagem típica ioruba, visto que a maioria dos estudantes desconhece o vocabulário utilizado e poucos pesquisam seus significados para realizar uma leitura mais aprofundada e contextualizada. O que motiva discursos de incompreensão vocabular dos estudantes, algo que se modifica rapidamente ao iniciar a contextualização do texto, analisarmos os personagens e a simbologia. Logo, novamente o preconceito volta à baila das discussões, especialmente pela associação ao Demônio.

Notamos que os estudantes, em sua maioria, demonstraram aversão aos contos. 
Esse sentimento se justifica pela doutrina religiosa, enquanto poucos comentaram e expuseram conhecimento prévio sobre eles. Somente em momentos externos a aula, os estudantes praticantes de religiões africanas tiveram coragem de procurar a professora para conversar sobre o texto. Logo, o objetivo seria conceder voz para estes contribuírem e participarem nas discussões em sala.

O que ocorrerá com as crianças negras é uma ausência de conteúdo que conte sua história e que faça com que, no futuro, elas tendam a transformar-se em adultos problemáticos em suas afirmações como sujeitos. A construção da identidade sofrerá forte influência de todas estas representações sociais (MARIOSA; REIS, 2011, p. 48).

Para tanto, optamos pela produção escrita de caráter biográfico "Experiências e vivências com sua religião", a qual o leitor inicial seria apenas a professora, como estratégia inicial para iniciar o processo de rompimento do silenciamento dos estudantes, praticados nos debates especialmente pelos discursos de ódio, os quais possuíam como palavras-chave: Demônio, pecado e inferno.

$\mathrm{Na}$ simbologia de cores da civilização européia, a cor preta representa uma mancha moral e física, a morte e a corrupção, enquanto a branca remete à vida e à pureza. Nesta ordem de idéias, a Igreja Católica fez do preto a representação do pecado e da maldição divina. Por isso, nas colônias ocidentais da África, mostrou-se sempre Deus como um branco velho de barba e o Diabo um moleque preto com chifrinhos e rabinho (MUNANGA, 2009, p. 29).

Os textos biográficos representavam, em suma, pedidos de socorro, por meio dos relatos recobertos por tristeza, raiva e incompreensão. Notamos que o preconceito estava presente na maioria das produções, pois estudantes de outras religiões também relataram situações em que sofreram preconceito e/ou foram silenciadas de alguma forma pela sociedade.

[...] verifiquei que a literatura corresponde a uma necessidade universal que deve ser satisfeita sob pena de mutilar a personalidade, porque pelo fato de dar forma aos sentimentos e à visão do mundo ela nos organiza, nos liberta do caos e portanto, nos humaniza (CANDIDO, 2011, p. 188). 
Logo, Iemanjá e Iansã surgiram nos relatos das estudantes, tanto em forma de abuso, quanto da opressão sofrida. Dessa forma, a religião minimizou-se diante de situações comuns. E elencou-se que as orixás deveriam representar não somente a religião que evocam, mas sim a força e a resistência a todo tipo de opressão. Nessa verve, a sequência didática concentrou-se, então, em destacá-las a partir dos relatos de superação à opressão presente nos contos.

Assim, foram realizadas diversas pesquisas relacionadas ao papel da mulher na religião, permitindo a manifestação das diferentes religiões dos estudantes, na qual Maria destacou-se entre os católicos, Ester e Rute entre os evangélicos, e outros estudantes pesquisaram, ainda, sobre outras orixás mulheres, descentralizando, a partir da ampliação de conhecimento, o diálogo sobre religiosidade na sala de aula.

Em seguida, os textos africanos foram relidos pela turma, oportunizando a revisão dos discursos iniciais embasados apenas no preconceito, especialmente por meio da valorização da Educação das Relações Étnico Raciais de combate ao racismo no ambiente escolar favorecida pela Lei 10.639, visto que a experiência em sala de aula com os contos levantaram questões que puderam revelar atitudes racistas e a desconstruindo essa prática pela atividade de leitura e compartilhamento de textos que protagonizam outros sujeitos, olhares múltiplos da sociedade brasileira.

Notamos que o contexto social ganhou maior significação, a partir das pesquisas, e da relação com o texto biográfico, por meio das ações de Iemanjá e Iansã. Possibilitando, assim, que os estudantes demonstrassem um conhecimento articulado, ao contrário do centralizado das aulas iniciais, o qual evidenciou-se, especialmente por meio da produção de um texto dissertativo "Preconceito instaurado: relações de conflito e poder entre as diferentes religiões praticadas no Brasil”.

A experiência com os textos africanos de temática religiosa em sala de aula desenvolveu-se a partir de uma sequência didática centrada na leitura do texto literário e da produção de textos, contemplando tanto a proposta curricular, quanto os conteúdos apresentados nos parâmetros curriculares, não se distanciando do objetivo central das aulas, logo, não havendo impedimentos para a sua realização. 


\section{CONSIDERAÇÕES}

Procuramos, ao longo deste trabalho, demonstrar o papel do texto literário de origem africana e afro-brasileira de temática religiosa para a aplicação e manutenção da Lei ${ }^{\circ}$ 10.639, a qual determina o ensino de História e Cultura Afro-brasileira em sala de aula, visto que:

É responsabilidade da escola estar atenta para a escolha do acervo de sua biblioteca, devendo optar por livros que contribuam para a formação de uma identidade positiva do negro e, simultaneamente, proporcionar aos alunos não negros o contato com a diversidade e as especificidades da cultura africana, deixando, assim, para trás, uma visão estereotipada e preconceituosa das idiossincrasias dos referenciais afrodescendentes (MARIOSA; REIS, 2011, p. 47).

O desenvolvimento desta pesquisa permitiu-nos compreender que os estudantes negros praticantes de religião de matriz africana sofrem no processo de construção e representação de sua identidade, por meio da opressão e silenciamento impostos pela sociedade e pela tradição religiosa dominante.

Como estratégia para mediar e possibilitar a construção identitária desses estudantes, optamos pela leitura de textos literários, pois conforme Candido (2011, p. 177) “[...] talvez não haja equilíbrio social sem a literatura [...] ela é fator indispensável de humanização e, sendo assim, confirma o homem na sua humanidade [...]”.

Iemanjá e Iansã são mais do que personagens mitológicas do candomblé e da umbanda, são exemplos de mulheres negras que vivenciaram e venceram a luta social contra a opressão e o silenciamento imposto pela sociedade patriarcal. São orixás, mas também são mulheres, mães e guerreiras.

É importante compreender que a sequência didática aqui apresentada deve estar em constante revisão, especialmente ao considerarmos os diferentes contextos e perfis dos estudantes. Dessa forma, acreditamos que o diálogo entre todas as instâncias que compõem a comunidade escolar é fundamental para a revisão de práticas e costumes, que, em sua maioria, são enraizados pelo preconceito.

Existem muitas Iemanjás e Iansãs na sala de aula, ainda silenciadas e oprimidas, seja pelo discurso do professor ou do livro didático, seja pelo discurso dos demais alunos, 
pois as raízes da escravidão ecoam no ódio e preconceito, especialmente em relação à tradição religiosa dos negros. A umbanda e o candomblé são paz e amor.

\section{REFERÊNCIAS}

BRASIL. Lei $n^{\circ} 10.639$, de 9 de janeiro de 2003. Altera a Lei $n^{\circ} 9.394$, de 20 de dezembro de 1996, que estabelece as Diretrizes e Bases da Educação Nacional, para incluir no currículo oficial da Rede de Ensino a obrigatoriedade da temática "História e Cultura Afro-Brasileira". Diário Oficial da União, Brasília, 15 jan. 2003. Disponível em: $<$ http://www.planalto.gov.br/ccivil_03/leis/2003/110.639.htm>. Acesso em: 10 jan. 2019.

BRASIL. Secretaria de Educação Fundamental. Parâmetros curriculares nacionais: pluralidade cultural. Brasília: MEC, 1997, p. 115-166.

CANDIDO, A. O direito à literatura. In: CANDIDO, A. Vários escritos. 5.ed. Rio de Janeiro: Ouro sobre Azul, 2011, p. 171-193.

CONCEIÇÃO, J. S. Quando o assunto é sobre religiões de matriz africana: lei 10.639/2003. Revista da FAEEBA - Educação e Contemporaneidade, Salvador, v. 25, n. 45, p.113-126, 2016. Disponível em $:<$ https://www.revistas.uneb.br/index.php/faeeba/article/view/2289/1595>. Acesso em: 10 jan. 2019.

GINZBURG, J. Autoritarismo e literatura: a história como trauma. Vidya, Santa Maria, Centro Universitário Franciscano, v. 19, n. 33, p. 43-51, 2000. Disponível em: $<$ https://periodicos.ufn.edu.br/index.php/VIDYA/article/view/533>. Acesso em: 10 jan. 2019.

GOMES, R. Análise e interpretação de dados de pesquisa qualitativa. In: DESLANDES, S. F. Pesquisa social: teoria, método e criatividade. 28. ed. Petrópolis, RJ: Vozes, 2009, p.79-108.

MARIOSA, G. S.; REIS, M. G. A influência da literatura infantil afro-brasileira na construção das identidades das crianças. Estação Literária. Londrina, Vagão-volume 8, parte A, p. 42-53, dez. 2011. Disponível em: <http://www.uel.br/pos/letras/EL/vagao/EL8AArt06.pdf>. Acesso em: 12 fev. 2019.

MARTINS, A. A punição de Iemanjá. In: MARTINS, A. Lendas de Exu. 2.ed. Rio de Janeiro: Pallas, 2008, p. 126-129.

MEIRELLES, M. Dos terreiros para a sala de aula: as religiões de matriz africana no RS, limites e possibilidades. Anais do Congresso Internacional da Faculdade EST. São Leopoldo: EST, v.1, p.146-156, 2012. Disponível em: $<$ http://anais.est.edu.br/index.php/congresso/article/download/92/13 > Acesso em: 15 fev. 2019. 
MUNANGA, K. Negritude: usos e sentidos. Belo Horizonte: Autêntica Editora, 2009. (Coleção Cultura Negra e Identidades).

OLIVEIRA, A. P. et al. O Xangô na sala de aula: dilemas da identidade religiosa afrobrasileira em Alagoas. Interações - Cultura e Comunidade, Belo Horizonte, Brasil, v.8, n.14, p. 261-279, jul./dez, 2013. Disponível em: <https://doi.org/10.5752/P.19832478.2013v8n14p261>. Acesso em: 12 fev. 2019.

SANTOS, C. R. S.; WIELEWICKI, V. H. G. Literatura de autoria de minorias étnicas e sexuais. In: BONNICI, T.; ZOLIN, L. O. (orgs.). Teoria literária: abordagens históricas e tendências contemporâneas. 3. ed. rev. e ampl. Maringá: Eduem, 2009, p. 337-354.

SISTO, C. A pele de Oiá-Iansã. In: SISTO, C. Mãe África: mitos, lendas, fábulas e contos. São Paulo: Paulus, 2007, p. 101-105.

ZEICHNER, K. M.; DINIZ-PEREIRA, J. E. Pesquisa dos educadores e formação docente voltada para a transformação social. Cadernos de Pesquisa, v. 35, n. 125, p. 63-80, maio/ago. 2005. Disponível em: <https://doi.org/10.1590/S0100-15742005000200005>. Acesso em: 15 fev. 2019.

Recebido em: 19 jun. 2020.

Aceito em: 03 ago. 2020. 